\title{
Carotid plaque is a predictor of major adverse cardiac and cerebrovascular events in patients undergoing coronary angiography
}

\author{
La presencia de placa carotídea es predictor de eventos adversos cardiacos y \\ cerebrovasculares en sujetos sometidos a coronariografía
}

\author{
Raúl Franco-Gutiérrez ${ }^{1 *}$, Alberto J. Pérez-Pérez ${ }^{1}$, Virginia Franco-Gutiérrez², \\ Raymundo Ocaranza-Sánchez ${ }^{1}$, Ana Testa-Fernández ${ }^{1}$, Manuel L. López-Reboiro³, \\ Andrea López-López ${ }^{1}$, Melisa Santás-Álvarez ${ }^{1}$, María G. Crespo-Leiro ${ }^{4}$ and Carlos González-Juanatey ${ }^{1}$
}

${ }^{1}$ Department of Cardiology, Hospital Universitario Lucus Augusti (HULA), Lugo; ${ }^{2}$ Department of Otolaryngology, Hospital Universitario Marques de Valdecilla, Santander; ${ }^{3}$ Department of Internal Medicine, Hospital Universitario Lucus Augusti (HULA), Lugo; ${ }^{4}$ Department of Cardiology, Complejo Hospitalario Universitario A Coruña (CHUAC), Instituto Investigación Biomédica A Coruña (INIBIC), Universidad da Coruña (UDC), A Coruña. Spain

\begin{abstract}
Background: Carotid disease, measured as carotid intima-media thickness (CIMT) and carotid plaque (CP), is associated with major adverse cardiac and cerebrovascular events (MACCE) in people without the previous atherosclerotic disease; however, there are few published data in patients undergoing coronary angiography. The aim of the study is to determinate if the carotid disease is associated with MACCE after coronary angiography. Methods: $A$ total of 390 consecutive patients underwent coronary angiography after exercise echocardiography and carotid ultrasonography between 2002 and 2013. MACCE was defined as stroke, myocardial infarction due to atherosclerosis progression or death due to a stroke or cardiac event. Results: Two patients were lost (0.5\%). During a mean follow-up of 6.0 years (standard deviation of 2.9), 52 patients (13.4\%) suffered MACCE. 1, 5, and 10 years, event-free survival was $96.4 \%(1.0), 88.7 \%(1.7)$, and $81.4 \%$ (2.8), respectively. Event rates at 10 years were higher in the CP group $(23.2 \%$ vs. $10.2 \%, p=0.013)$ and in the CIMT $>0.9 \mathrm{~mm}$ group $(25.9 \%$ vs. $13.3 \%, p=0.023$ ). Multivariate analysis showed smoking habit (hazard ratio [HR] 2.51, 95\% confidence interval [CI] 1.36-4.62, $p=0.003$ ), glomerular filtration rate (HR 0.98, $95 \% \mathrm{Cl}$ 0.98-0.99), aortic stenosis (HR 2.99, 95\% Cl 1.24-7.21, $p=0.014$ ), incomplete/no coronary revascularization (HR 1.97,95\% Cl 1.06-3.67, $p=0.033$ ), insulin treatment (HR 2.63, 95\% $C l 1.30-5.31, p=0.006)$, and $C P(H R 2.36,95 \% C l 1.02-5.44, p=0.044)$ as predictors of MACCE. Conclusions: $C P$ is an independent predictor of MACCE in patients undergoing coronary angiography.
\end{abstract}

Key words: Carotid ultrasonography. Carotid plaque. Coronary artery disease. Major adverse cardiac and cerebrovascular events. Spain.

Correspondence:

*Raúl Franco Gutiérrez

E-mail: raul.franco.gutierrez@sergas.es
Available online: 09-08-2019 Arch Cardiol Mex (Eng). 2019;89(1):1-7 www.archivoscardiologia.com 2604-7063 @ 2018 Instituto Nacional de Cardiología Ignacio Chávez. Publicado por Permanyer México SA de CV. Este es un artículo Open Access bajo la licencia CC BY-NC-ND (http://creativecommons.org/licenses/by-nc-nd/4.0/). 


\section{Resumen}

Introducción: La enfermedad carotídea, definida como grosor de íntima media (GIMC) y placa (PC), se asocia con eventos adversos cardiacos y cerebrovasculares (EACC) en sujetos sin aterosclerosis previa; sin embargo hay pocos datos en pacientes sometidos a coronariografía. El objetivo del estudio es determinar si la enfermedad carotídea se asocia a EACC en pacientes remitidos a coronariografía. Métodos: Entre 2002 y 2013390 pacientes fueron sometidos a coronariografía tras ecocardiograma de esfuerzo y ecografía carotídea. Se definió EACC como accidente cerebrovascular, infarto de miocardio por progresión aterosclerótica o muerte por accidente cerebrovascular o causa cardiaca. Resultados: Durante un seguimiento medio de 6 años (desviación estándar 2, 9) se registraron 2 pérdidas y 52 eventos (13,4\%). La supervivencia media libre de eventos a uno, cinco y diez años fue $96.4 \%$ (1.0), $88.7 \%$ (1.7) y $81.4 \%$ (2.8). Hubo mayor número de eventos a 10 años en el grupo de $P C(23.2 \%$ frente $10.2 \%, p=0.013)$ y $G I M C>0.9 \mathrm{~mm}(25,9 \%$ frente $13.3 \%, p=0.023)$. En el análisis multivariado los predictores de EACC fueron tabaquismo (hazard ratio [HR] 2.51, intervalo de confianza [IC] al 95\% 1.36-4.62, $p=0.003$ ), filtrado glomerular renal (HR 0.98 IC95\% 0.98-0.99), estenosis aórtica (HR 2.99, IC 95\% 1.24-7.21, $p=0.014$ ), revascularización incompleta/no revascularización (HR 1.97, IC 95\% 1.06-3.67, $p=0.033$ ), tratamiento con insulina (HR 2.63, IC 95\% 1.30-5.31, $p=0.006)$ y PC (HR 2.36, 95\% Cl 1.02-5.44, $p=0.044)$. Conclusiones: La PC es un predictor independiente de EACC en pacientes sometidos a coronariografía.

Palabras clave: Ecografía carotídea. Placa carotídea. Enfermedad arterial coronaria. Eventos adversos cardiacos y cerebrovasculares. España.

\section{Introduction}

There is well-documented evidence for atherosclerosis as a systemic disorder ${ }^{1-12}$. Postmortem studies have shown a strong correlation between carotid and coronary artery disease $(C A D)^{1-3}$. In the same line, carotid intima-media thickness (CIMT) and/or the presence of plaque carotid plaque (CP) have been identified as independent predictors of myocardial infarction (MI), stroke and death in asymptomatic and presumably healthy patients ${ }^{4-12}$ improving the ability of risk functions to predict cardiovascular events ${ }^{13}$.

Conversely to people without previous cardiovascular disease, there are few studies correlating carotid disease and new cardiovascular events in patients with ischemic heart disease, some of them showing contradictory results ${ }^{14-20}$.

The aim of our study is to ascertain whether the carotid disease is a predictor of major adverse cardiac and cerebrovascular events (MACCE) in patients undergoing a coronary angiography regarding previous treadmill exercise stress echocardiography results.

\section{Methods}

\section{Study population}

This is a single-center retrospective study of patients submitted to coronary angiography after treadmill exercise stress echocardiography and carotid ultrasound were performed. From January 1, 2002, to December 31, 2013, 390 consecutive Caucasian patients older than
18 years with suspected CAD underwent coronary angiography in multiple projections using standard technique regarding exercise echocardiography results and physician's in charge of the patient criteria, mainly due to the persistence of symptoms. All patients signed an informed consent before testing. The study was approved by the Regional Ethics Committee.

Demographic, clinical, rest and exercise echocardiography, carotid, angiography, and treatment data were collected. Prior CAD was defined as previous $\mathrm{Ml}^{21}$, coronary revascularization, or angiographic documentation of any coronary stenosis $\geq 50 \%$. Prior vascular disease was defined as prior CAD, stroke, transient ischemic attack or peripheral artery disease.

\section{Rest and treadmill exercise stress echocardiography}

Rest and exercise echocardiography was carried out according to the current European and American guidelines at the time of their performance $22-24$.

\section{Carotid ultrasonography}

Carotid scans were performed immediately after stress test with the same exercise echocardiography ultrasound equipment using a high-resolution, non-harmonic B-mode ultrasound system (Philips Sonos 5500 between 2002 and 2005 and Philips iE33 after 2005; Philips Medical Systems) with a linear array (3-11 MHz) transducer. CP was defined as a focal structure encroaching into the 
arterial lumen by $>0.5 \mathrm{~mm}$, a distinct area of CIMT $>50 \%$ than the adjacent wall or CIMT > $1.5 \mathrm{~mm}^{25-28}$. CIMT was assessed as stated by the atherosclerosis risk in communities study ${ }^{6}$ and current guidelines ${ }^{25-28}$ using a semiautomated edge detection algorithm (Qlab; Philips 110 Medical Systems, Andover, MA, USA).

CIMT age- and sex-specific percentile values were defined according to previously published data in our country ${ }^{29}$.

Carotid ultrasonography stored images were retrospectively analyzed by two imaging expert cardiologists blinded to MACCE. In case of disagreement, a third expert was consulted.

\section{Coronary angiography}

The significant angiographic disease was defined as stenosis $\geq 50 \%$ by visual assessment in any major epicardial arteries or their branches. CAD treatment was recorded as medical, balloon percutaneous coronary intervention $(\mathrm{PCl})$, bare metal and drug-eluting stent $\mathrm{PCl}$ or coronary artery bypass grafting (CABG). Complete revascularization was defined as the treatment of any significant CAD in vessels $\geq 1.5 \mathrm{~mm}$ as estimated on the diagnostic angiogram during the local Heart Team conference.

\section{Follow-up and end point}

Follow-up data were obtained from the hospital database, medical records, and death certificates. In case of doubt, the Regional Mortality Registry was consulted. MACCE was defined as MI due to atherosclerosis progression, stroke and death due to Ml, stroke, life-threating arrhythmias, cardiac arrest or unexpected and otherwise-unexplained sudden death. MI was defined as specified by the third universal definition of Ml expert consensus document ${ }^{21}$. Patients with $\mathrm{Ml}$ due to in-stent restenosis or thrombosis were censored at the time of the event. Stroke was defined as a loss of neurological function caused by an ischemic event, lasting for $>24 \mathrm{~h}$ or leaving residual signs.

\section{Statistical analysis}

Categorical variables were reported as percentages and continuous variables as mean (standard deviation) when they are normally distributed or median (interquartile range) when their distribution departed from normal.

Cumulative events curves were calculated by Kaplan-Meier method and compared by log rank test.
Table 1. Clinical and biochemical baseline characteristics of enrolled patients

\begin{tabular}{|l|c|}
\hline Variable & All patients $\mathrm{n}=390(\%)$ \\
\hline Age (years) & $66.0(10.5)$ \\
\hline Male sex (\%) & $296(75.9)$ \\
\hline BMI $\left(\mathrm{Kg} / \mathrm{m}^{2}\right)$ & $28.4(3.9)$ \\
\hline Hypertension & $239(61.3)$ \\
\hline Hypercholesterolemia & $245(62.8)$ \\
\hline Diabetes mellitus & $131(33.6)$ \\
\hline Smoking habit & $191(49.0)$ \\
\hline Family history of premature CAD & $44(11.3)$ \\
\hline Obesity (BMI $\left.\geq 30 \mathrm{Kg} / \mathrm{m}^{2}\right)$ & $116(29.7)$ \\
\hline Atrial fibrillation & $37(9.5)$ \\
\hline Prior CAD & $205(52.6)$ \\
\hline Prior vascular disease & $234(60.0)$ \\
\hline Chest pain & $341(87.4)$ \\
\hline Fasting plasma glucose (mg/dL) & $114.1(33.0)$ \\
\hline GFR (ml/min/1.73 m²) & $77.0(24.1)$ \\
\hline Total Cholesterol (mg/dL) & $175.9(44.5)$ \\
\hline Low-density lipoprotein (mg/dL) & $104.7(36.2)$ \\
\hline High-density lipoprotein (mg/dL) & $41.6(11.0)$ \\
\hline Triglycerides & $152.9(106.9)$ \\
\hline B & \\
\hline
\end{tabular}

BMI: body mass index, CAD: coronary artery disease, GFR: glomerular filtration rate.

Cox's proportional hazards models were performed for univariate and multivariate analysis of the endpoint. In multivariate analysis, backward stepwise selection was used with an entry set at 0.2 significance level and a retention set of $0.1 . p<0.05$ was considered statistically significant.

The statistical analysis was carried out with IBM SPSS Statistics for Windows, Version 20.0. (Armonk, NY).

\section{Results}

Of all patients, $2(0.5 \%)$ were lost during follow-up. Baseline characteristics of subjects are summarized in tables 1 and 2.

\section{Outcomes}

During a mean follow up of 6.0 (2.9) years, 60 patients deceased $(15.5 \%)$. The causes of death were 
Table 2. Echocardiographic, carotid and angiographic baseline characteristics and medical treatment at discharge

\begin{tabular}{|c|c|}
\hline Variable & All patients $n=390(\%)$ \\
\hline Left ventricular ejection fraction (\%) & $60.4(8.49)$ \\
\hline Left ventricular ejection fraction $<50 \%$ & $42(10.8)$ \\
\hline Mitral valve regurgitation & $239(61.3)$ \\
\hline Aortic valve stenosis & $20(5.1)$ \\
\hline Aortic valve regurgitation & $131(33.6)$ \\
\hline Positive stress echocardiography & $283(72.6)$ \\
\hline Metabolic equivalents & $7.46(2.8)$ \\
\hline Mean CIMT (mm) & $0.88(0.21)$ \\
\hline CIMT $>0.9 \mathrm{~mm}$ & $171(43.8)$ \\
\hline Mean CIMT percentile $\geq 75^{\text {th }}$ & $236(60.5)$ \\
\hline CP & $273(70.0)$ \\
\hline$C A D \geq 50 \%$ & $295(75.6)$ \\
\hline 1 vessel & $115(29.5)$ \\
\hline 2 vessels & $89(22.8)$ \\
\hline 3 vessels & $91(23.4)$ \\
\hline $\mathrm{PCl}$ & $165(42.3)$ \\
\hline CABG & $31(10.5)$ \\
\hline Incomplete/no revascularization & $191(49.0)$ \\
\hline Beta-blockers & $315(80.8)$ \\
\hline Calcium channel blockers & $89(22.8)$ \\
\hline Nitrates & $132(33.8)$ \\
\hline Statins & $349(89.5)$ \\
\hline Ezetimibe & $22(5.6)$ \\
\hline Antidiabetic drugs & $79(20.3)$ \\
\hline Insulin & $35(9)$ \\
\hline Antiplatelet drugs & $351(90.0)$ \\
\hline Oral anticoagulants drugs & $29(7.4)$ \\
\hline
\end{tabular}

CABG: coronary artery bypass grafting, CAD: coronary artery disease, CIMT: carotid intima-media thickness, CP: carotid plaque, PCI: percutaneous coronary intervention.

non-cardiovascular events (fundamentally neoplasms) in 28 patients $(46.7 \%)$, sudden death in 17 subjects $(28.3 \%)$, MI in 5 patients $(8.3 \%)$, heart failure in 5 patients $(8.3 \%)$, arrhythmia in 3 patients $(5 \%)$, and stroke in 2 patients (3.3\%). MI was diagnosed in 42 patients $(10.8 \%), 16$ of them related to in-stent restenosis or thrombosis, and 12 patients suffered stroke (3.1\%).
In the subgroup of 67 patients without significant CAD and previous vascular disease 29 subjects (43.28\%) had CP in carotid ultrasonography. Neither AMI nor deaths were observed, just one stroke was reported in the subgroup of patients with $\mathrm{CP}$.

MACCE was recorded in 52 subjects (13.4\%). Mean annual event rate was $2.1 \%$. Kaplan-Meier event-free survival was $96.4 \%$ (1.0) at 1 year, $88.72 \%$ (1.7) at 5 years, and $81.35 \%(2.8)$ at 10 years.

MACCE was higher in CIMT > $0.9 \mathrm{~mm}$ group with a mean annual event rate of $1.7 \%$ in the CIMT $\leq 0.9 \mathrm{~mm}$ compared to $2.7 \%$ in the CIMT $>0.9 \mathrm{~mm}$ group. Cumulative incidence of MACCE was $1.9 \%, 7.8 \%$, and $13.3 \%$ versus $5.9 \%, 15.8$, and $25.9 \%(p=0.023)$ at 1,5 , and 10 years, respectively. CP presence was also predictor of MACCE with a mean annual event rate of $0.8 \%$ and cumulative incidence of $2.6 \%, 7.1$ and $10.2 \%$ at 1,5 , and 10 years in the $\mathrm{CP}$ absence group and a mean annual event rate of $2.8 \%$ and cumulative incidence of MACCE at 1,5 , and 10 years of $4.1 \%, 13.2 \%$, and $23.2 \%$ in the CP presence group ( $p=0.013)$. Fig. 1 represents cumulative incidence of MACCE depending on carotid ultrasound characteristics.

\section{Predictors of outcome}

Univariate analysis showed age (Hazard Ratio [HR] $1.03, p=0.040)$, diabetes mellitus $(\mathrm{HR}=2.32, p=0.002)$, smoking habit $(\mathrm{HR}=1.87, p=0.030)$, glomerular filtration rate (GFR) $(H R=0.98, p=0.002)$, baseline left ventricular ejection fraction $(\mathrm{HR}=0.96, p=0.040)$, presence of aortic stenosis (HR $3.29, p=0.007$ ), metabolic equivalents in stress test ( $\mathrm{HR}=0.90, p=0,046)$, $\mathrm{CP}(\mathrm{HR}=2.41, p=0.017)$, $\mathrm{CIMT}>0.9 \mathrm{~mm}(\mathrm{HR}=1.87$, $p=0.025)$, number of coronary arteries affected $(\mathrm{HR}=1.43, p=0.006)$, incomplete revascularization $(\mathrm{HR}=2.62, p=0.001)$, and nitrates and insulin treatment $(\mathrm{HR}=1.73, p=0.049$ and $\mathrm{HR}=2.97, p=0.001$ respectively). Multivariate analysis of combined end point is represented in table 3 .

\section{Discussion}

The present study shows that $\mathrm{CP}$ is an independent predictor of MACCE in patients undergoing coronary angiography.

Held et al. failed to demonstrate a significant association between CIMT or CP and cardiovascular events in patients with stable CAD; however, the diagnosis of angina was clinical ${ }^{14}$. Petersen et al. identified $\mathrm{CP}$ as a predictor of mortality in cardiological patients, but only 


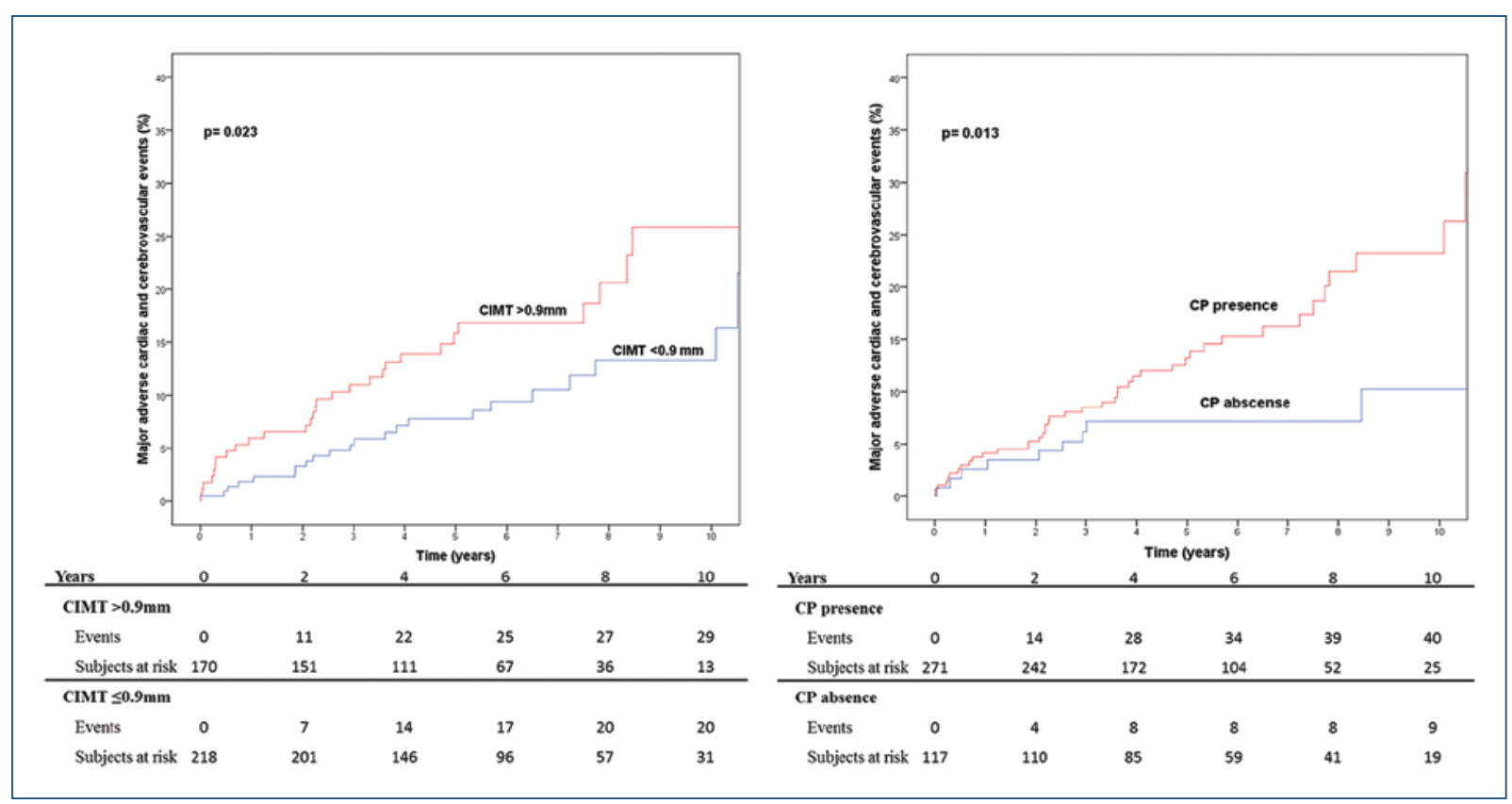

Figure 1. Cumulative incidence of major adverse cardiac and cerebrovascular events depending on carotid ultrasound characteristics (carotid plaque or carotid intima-media thickness $>0.9 \mathrm{~mm}$ ).

Table 3. Multivariate analysis of MACCE

\begin{tabular}{|l|c|c|c|}
\hline Variable & HR & $95 \%$ CI & $\boldsymbol{p}$ value \\
\hline Smoking habit & 2.51 & $1.36-4.62$ & 0.003 \\
\hline GFR & 0.98 & $0.97-0.99$ & 0.043 \\
\hline Aortic stenosis & 2.99 & $1.24-7.21$ & 0.014 \\
\hline Incomplete/no revascularization & 1.97 & $1.06-3.67$ & 0.033 \\
\hline Nitrates treatment & 1.73 & $0.95-3.18$ & 0.075 \\
\hline Insulin treatment & 2.63 & $1.30-5.31$ & 0.006 \\
\hline CP & 2.36 & $1.02-5.44$ & 0.044 \\
\hline
\end{tabular}

Cl: confidence interval, HR: hazard ratio, rest of abbreviations as in table 1 and 2, MACCE: major adverse cardiac and cerebrovascular events, GFR: glomerular filtration rate, $\mathrm{CP}$ : carotid plaque.

$64 \%$ of them were ischemic and they did not take into account the approach done (invasive or medical treatment $)^{15}$. Sirimarco et al. also identified CP as an independent predictor of coronary events in patients with atherosclerosis and/or CAD. CAD was defined as stable angina, previous $\mathrm{MI}$ or history of unstable angina, $\mathrm{PCl}$ or CABG but there was no angiographic assessment of $C A D^{16}$.

Studies involving patients with CAD assessed by angiography showed consistent results; however, significant $\mathrm{CAD}$ and end points definitions were heterogeneous.
Komorovsky identified echogenic or calcified $\mathrm{CP}$ as a predictor of cardiac death, nonfatal $\mathrm{Ml}$ or unstable angina in patients with acute coronary syndrome. Both, selection criteria of the subjects and definition of significant CAD $(\geq$ $70 \%$ luminal narrowing) were different from our study ${ }^{17}$. Zielinski et al. and colleagues showed CIMT as a predictor of death and MACCE, defined as death, stroke or MI, in hypertensive patients with CAD defined as $\geq 50 \%$ stenosis ${ }^{18}$. Park found CP as a predictor of cardiac death, stroke or $\mathrm{MI}$ in a cohort of patients with significant $\mathrm{CAD}$ (defined as stenosis $>50 \%$ ). Contrary to our study all patients had significant $C A D$, they did not evaluate the impact of medical intervention and they included stent restenosis and target vessel revascularization in the end point, not only coronary atherosclerosis progression ${ }^{19}$. Finally, Steinvil et al. identified carotid atherosclerosis as a predictor of all-cause mortality, Ml, stroke, and any CAD revascularization in patients with any coronary stenosis > $70 \%$ but not in patients without CAD. Similar to the park, medical treatment was not systematically registered, and significant CAD definition was different from ours ${ }^{20}$.

Pathological studies indicate that CIMT mainly represents medial hypertrophy, whereas $\mathrm{CP}$ probably represents a later atherogenesis stage ${ }^{1-3,25-27,30}$. According to this theory, CP might identify a subgroup of people with more diffuse and greater progression of atherosclerotic disease despite secondary prevention measures. 
Besides CP, smoking habit, GFR, aortic stenosis, incomplete or no revascularization, and insulin treatment were MACCE predictors. Insulin treatment could reflect a subgroup of more advanced diabetes mellitus with severe organ damage or metabolic memory phenomenon $^{31,32}$. It is not surprising to found aortic stenosis as a MACCE predictor. Aortic stenosis and CAD share physiopathological mechanism ${ }^{33}$ and furthermore, previous studies have shown similar results ${ }^{34}$. Several studies have correlated chronic kidney disease ${ }^{35,36}$ and smoking habit ${ }^{36-38}$ to cardiovascular events and incomplete revascularization to worse prognosis in patients with ischemic heart disease ${ }^{22,39}$. Although left ventricular ejection fraction has been well recognized as one of the most powerful indicators of adverse prognosis, ${ }^{22,40}$ we did not find significant association in our study. The reason could be because only $34(8.7 \%)$ patients had mid-range and $8(2.1 \%)$ reduced left ventricular ejection fraction. Finally, patients without CAD and previous vascular disease have an excellent prognosis.

The study has some drawbacks: it is a retrospective single institution study with low recruitment rate and therefore it is hampered by the use of different equipment and methods of image storage and new therapeutic devices or treatments that could have influenced in the final results. Due to the fact that the number of patients without previous vascular disease submitted to treadmill exercise stress echocardiography and coronary angiography yearly is low, one possible solution could be to perform a multicenter prospective study. Second, the CAD stenosis percentage was assessed visually and not using more accurate tools (intravascular ultrasound or optical coherence tomography) or by physiological assessment of CAD stenosis in the cardiac catheterization laboratory (fractional flow reserve). This is also a consequence of a retrospective study design (some techniques were not available at the time of the angiography performance) and reflects the usual clinical practice in catheterization laboratories where intermediate stenosis are treated if there is evidence of ischemia in previously performed stress test and the methods mentioned above are seldom used in case of negative stress test or at the interventional cardiologist criteria in case of no prior stress test available.

\section{Conclusions}

$\mathrm{CP}$ is an independent predictor of future MACCE in patients undergoing coronary angiography. The subgroup of patients without CAD and previous vascular disease has an excellent prognosis. CP presence could justify a more aggressive therapeutic approach in primary and secondary prevention.

\section{Acknowledgments}

The authors want to thank Miss Leonor Ortega Fernández for her assistance in data collection.

\section{Funding}

This research was supported by the "Fundación Ramón Domínguez para la investigación, desarrollo e innovación biosanitaria," a non-profit foundation created by the merger of two Hospital Foundations [Grant code ECOES].

\section{Conflicts of interest}

The authors declare that they have no competing interest.

\section{Ethical disclosures}

The study has been approved by the Regional Ethics committee: "Comité Territorial de Ética de Investigación de Santiago-Lugo" with the committee's reference number 2015/270, and have therefore been performed in accordance with the ethical standards laid down in the 1964 Declaration of Helsinki and its later amendments or comparable ethical standards.

\section{References}

1. Iwakiri $T$, Yano $Y$, Sato $Y$, et al. Usefulness of carotid intima-media thickness measurement as an indicator of generalized atherosclerosis: findings from autopsy analysis. Atherosclerosis. 2012;225:359-62.

2. Mathur KS, Kashyap SK, Kumar V. Correlation of the extent and severity of atherosclerosis in the coronary and cerebral arteries. Circulation. 1963;27:929-34

3. Mitchell JR, Schwartz CJ. Relationship between arterial disease in different sites. A study of the aorta and coronary, carotid, and iliac arteries. Br Med J. 1962;1:1293-301.

4. Lorenz MW, Markus HS, Bots ML, Rosvall M, Sitzer M. Prediction of clinical cardiovascular events with carotid intima-media thickness: a systematic review and meta-analysis. Circulation. 2007;115:459-67.

5. Salonen JT, Salonen R. Ultrasonographically assessed carotid morphology and the risk of coronary heart disease. Arterioscler Thromb. 1991;11:1245-9.

6. Chambless LE, Heiss G, Folsom AR, et al. Association of coronary heart disease incidence with carotid arterial wall thickness and major risk factors: the atherosclerosis risk in communities (ARIC) study, 1987-1993. Am J Epidemiol. 1997;146:483-94.

7. Cao JJ, Arnold AM, Manolio TA, et al. Association of carotid artery intima-media thickness, plaques, and C-reactive protein with future cardiovascular disease and all-cause mortality: the cardiovascular health study. Circulation. 2007;116:32-8.

8. Lorenz MW, Schaefer C, Steinmetz H, Sitzer M. Is carotid intima media thickness useful for individual prediction of cardiovascular risk? Ten-year results from the carotid atherosclerosis progression study (CAPS). Eur Heart J. 2010;31:2041-8.

9. Rosvall M, Janzon L, Berglund G, Engström G, Hedblad B. Incident coronary events and case fatality in relation to common carotid intima-media thickness. J Intern Med. 2005;257:430-7. 
10. van der Meer IM, Bots ML, Hofman A, et al. Predictive value of noninvasive measures of atherosclerosis for incident myocardial infarction: the rotterdam study. Circulation. 2004;109:1089-94.

11. Plichart M, Celermajer DS, Zureik M, et al. Carotid intima-media thickness in plaque-free site, carotid plaques and coronary heart disease risk prediction in older adults. The three-city study. Atherosclerosis. 2011;219:917-24.

12. Mathiesen EB, Bønaa KH, Joakimsen O. Echolucent plaques are associated with high risk of ischemic cerebrovascular events in carotid stenosis: the tromsø study. Circulation. 2001;103:2171-5.

13. Peters SA, den Ruijter HM, Bots ML, Moons KG. Improvements in risk stratification for the occurrence of cardiovascular disease by imaging subclinical atherosclerosis: a systematic review. Heart. 2012;98:177-84

14. Held C, Hjemdahl P, Eriksson SV, et al. Prognostic implications of intima-media thickness and plaques in the carotid and femoral arteries in patients with stable angina pectoris. Eur Heart J. 2001;22:62-72.

15. Petersen C, Peçanha PB, Venneri L, et al. The impact of carotid plaque presence and morphology on mortality outcome in cardiological patients. Cardiovasc Ultrasound. 2006;4:16.

16. Sirimarco G, Amarenco P, Labreuche J, et al. Carotid atherosclerosis and risk of subsequent coronary event in outpatients with atherothrombosis. Stroke. 2013:44:373-9.

17. Komorovsky R, Desideri A, Coscarelli S, et al. Predictive value of associations between carotid and coronary artery disease in patients with acute coronary syndromes. Am J Cardiol. 2005;95:116-9.

18. Zielinski T, Dzielinska Z, Januszewicz A, et al. Carotid intima-media thickness as a marker of cardiovascular risk in hypertensive patients with coronary artery disease. Am J Hypertens. 2007;20:1058-64.

19. Park HW, Kim WH, Kim KH, et al. Carotid plaque is associated with increased cardiac mortality in patients with coronary artery disease. Int $\mathrm{J}$ Cardiol. 2013;166:658-63.

20. Steinvil A, Sadeh B, Bornstein NM, et al. Impact of carotid atherosclerosis on the risk of adverse cardiac events in patients with and without coronary disease. Stroke. 2014;45:2311-7.

21. Thygesen K, Alpert JS, Jaffe AS, et al. Third universal definition of myocardial infarction. Circulation. 2012;126:2020-35.

22. Task Force Members, Montalescot G, Sechtem U, et al. 2013 ESC guidelines on the management of stable coronary artery disease: the task force on the management of stable coronary artery disease of the European society of cardiology. Eur Heart J. 2013;34:2949-3003.

23. Finn SD, Blankenship JC, Alexander KP, et al. 2014 ACC/AHA/AATS/ PCNA/SCAI/STS focused update of the guideline for the diagnosis and management of patients with stable ischemic heart disease: a report of the American college of cardiology/American heart association task force on practice guidelines, and the American association for thoracic surgery, preventive cardiovascular nurses association, society for cardiovascular angiography and interventions, and society of thoracic surgeons. J Am Coll Cardiol. 2014;64:1929-49.

24. Pellikka PA, Nagueh SF, Elhendy AA, et al. American society of echocardiography recommendations for performance, interpretation, and application of stress echocardiography. J Am Soc Echocardiogr. 2007;20:1021-41.

25. Touboul PJ, Hennerici MG, Meairs S, et al. Mannheim intima-media thickness consensus. Cerebrovasc Dis. 2004;18:346-9.

26. Touboul PJ, Hennerici MG, Meairs S, et al. Mannheim carotid intima-media thickness consensus (2004-2006). An update on behalf of the advi- sory board of the $3^{\text {rd }}$ and $4^{\text {th }}$ watching the risk symposium, $13^{\text {th }}$ and $15^{\text {th }}$ European stroke conferences, Mannheim, Germany, 2004, and Brussels, Belgium, 2006. Cerebrovasc Dis. 2007;23:75-80.

27. Touboul PJ, Hennerici MG, Meairs S, et al. Mannheim carotid intima-media thickness and plaque consensus (2004-2006-2011). An update on behalf of the advisory board of the $3^{\text {rd }}, 4^{\text {th }}$ and $5^{\text {th }}$ watching the risk symposia, at the $13^{\text {th }}, 15^{\text {th }}$ and $20^{\text {th }}$ European stroke conferences, Mannheim, Germany, 2004, Brussels, Belgium, 2006, and Hamburg, Germany, 2011. Cerebrovasc Dis. 2012;34:290-6.

28. Stein $\mathrm{JH}$, Korcarz CE, Hurst RT, et al. Use of carotid ultrasound to identify subclinical vascular disease and evaluate cardiovascular disease risk: a consensus statement from the American society of echocardiography carotid intima-media thickness task force. Endorsed by the society for vascular medicine. J Am Soc Echocardiogr. 2008;21:93-111.

29. Grau M, Subirana I, Agis D, et al. Carotid intima-media thickness in the Spanish population: reference ranges and association with cardiovascular risk factors. Rev Esp Cardiol (Engl Ed). 2012;65:1086-93.

30. Inaba $Y$, Chen JA, Bergmann SR. Carotid plaque, compared with carotid intima-media thickness, more accurately predicts coronary artery disease events: a meta-analysis. Atherosclerosis. 2012;220:128-33.

31. Holman RR, Paul SK, Bethel MA, Matthews DR, Neil HA. 10-year follow-up of intensive glucose control in Type 2 diabetes. $N$ Engl $J$ Med. 2008;359:1577-89.

32. Nathan DM, Cleary PA, Backlund JY, et al. Intensive diabetes treatment and cardiovascular disease in patients with Type 1 diabetes. N Engl J Med. 2005;353:2643-53.

33. Milin AC, Vorobiof G, Aksoy O, Ardehali R. Insights into aortic sclerosis and its relationship with coronary artery disease. J Am Heart Assoc. 2014;3:e001111.

34. Aronow WS, Ahn C, Shirani J, Kronzon I. Comparison of frequency of new coronary events in older persons with mild, moderate, and severe valvular aortic stenosis with those without aortic stenosis. Am J Cardiol. 1998;81:647-9.

35. Schiffrin EL, Lipman ML, Mann JF. Chronic kidney disease: effects on the cardiovascular system. Circulation. 2007;116:85-97.

36. Piepoli MF, Hoes AW, Agewall S, et al. 2016 European guidelines on cardiovascular disease prevention in clinical practice: the sixth joint task force of the European society of cardiology and other societies on cardiovascular disease prevention in clinical practice (constituted by representatives of 10 societies and by invited experts) developed with the special contribution of the European association for cardiovascular prevention and rehabilitation (EACPR). Eur Heart J. 2016;37:2315-81.

37. Doll R, Peto R, Boreham J, Sutherland I. Mortality in relation to smoking: 50 years' observations on male British doctors. BMJ. 2004;328:1519.

38. Chow CK, Jolly S, Rao-Melacini P, et al. Association of diet, exercise, and smoking modification with risk of early cardiovascular events after acute coronary syndromes. Circulation. 2010;121:750-8.

39. Garcia S, Sandoval Y, Roukoz H, et al. Outcomes after complete versus incomplete revascularization of patients with multivessel coronary artery disease: a meta-analysis of 89,883 patients enrolled in randomized clinical trials and observational studies. J Am Coll Cardiol. 2013;62:1421-31.

40. Vlietstra RE, Assad-Morell JL, Frye RL, et al Survival predictors in coronary artery disease. Medical and surgical comparisons. Mayo Clin Proc. 1977;52:85-90. 